\title{
Traduções bíblicas católicas no Brasil (2000-2015)
}

Catholic Bible translations in Brazil (2000-2015)

\section{Johan Konings ${ }^{*}$}

Faculdade Jesuíta de Filosofia e Teologia (FAJE), Belo Horizonte, MG, Brasil

\section{Resumo}

Neste artigo, apresenta-se o que houve de novo nas traduções bíblicas católicas e ecumênicas produzidas no Brasil de 2000 a 2015. Constam, neste elenco: Bíblia de Jerusalém, Nova Bíblia Pastoral, Bíblia Sagrada Edição CNBB, Tradução Ecumênica da Bíblia TEB, Bíblia Sagrada Ave-Maria, Bíblia do Peregrino, Bíblia Sagrada Liga de Estudos Bíblicos LEB, Bíblia Sagrada de Aparecia. Mais atenção, porém, é dedicada a uma questão fundamental: a relação entre as traduções semântico-dinâmicas e as traduções formais, ambas julgadas necessárias para o uso comunitário, a leitura e o estudo individual da Bíblia. Apontam-se, também, alguns perigos ligados a ambos os tipos de tradução.

Palavras-chave: Bíblia. Linguagem. Tradução. Metáfora. Semântica. 


\section{Abstract}

This article presents the new or renewed Bible translations in Brazil, from catholic or ecumenical agencies, in the period of 2000-2015. The main translations are: Bíblia de Jerusalém, Nova Bíblia Pastoral, Bíblia Sagrada Edição CNBB, Tradução Ecumênica da Bíblia TEB, Bíblia Sagrada Ave-Maria, Bíblia do Peregrino, Bíblia Sagrada Liga de Estudos Bíblicos LEB, Bíblia Sagrada de Aparecia. The principal bias, however, is the methodological question of semantic dynamic translation versus formal translation. Both forms are considered necessary for communitarian and individual use. At the end are highlighted some dangers of both types of translation.

Keywords: Bible. Language. Translation. Metaphor. Semantics.

\section{Introdução}

Em diversas publicações anteriores, tratei das principais traduções bíblicas em voga no Brasil até o início deste milênio (KONINGS, 2009, 2014, p. 18-26). No presente artigo comentarei as traduções ou revisões notáveis — não as meras reedições — produzidas, desde 2000, no âmbito católico, com inclusão de algumas edições ecumênicas. Outro artigo no presente volume contempla as edições recentes provenientes das igrejas da Reforma.

\section{Novidades}

\section{A Bíblia da CNBB}

Em 2001, a Conferência Nacional dos Bispos do Brasil (CNBB) lançou, por um polo de diversas editoras, a primeira edição completa (Antigo e Novo Testamento) de sua Bíblia Sagrada (CNBB, 2001). A partir da segunda edição, de 2002, houve diversas revisões superficiais e mudanças de 
layout, sem modificações substanciais. A partir da terceira edição, a publicação vem sendo feita pela editora da $\mathrm{CNBB}$, em Brasília. O intuito é criar uma tradução de referência para a Igreja católica no Brasil, sem suprimir a enriquecedora pluralidade das traduções existentes. Tal projeto, porém, exige tempo; embora boa, a tradução atual ainda não está "no ponto", nem se apresenta como "oficial”. Por isso, iniciou-se uma revisão profunda, a fim de tornar o texto suficientemente seguro e, ao mesmo tempo, literariamente esmerado, para que dele se extraiam as leituras litúrgicas da missa e do breviário. Para essa finalidade ela terá de ser mais aderente aos textos originais, seguindo o modelo da Nova Vulgata (NOVA... Vaticana, 1986), que foi uma tentativa - tímida demais, segundo alguns - de aproximar mais a tradução latina "popular" de S. Jerônimo dos "originais" hebraico-aramaicos e gregos produzidos no início da era cristã ${ }^{1}$. Assim ela poderá tornar-se, em breve, uma "vulgata" brasileira.

\section{A edição totalmente revisada da Bíblia de Jerusalém}

A tradução da Bíblia de Jerusalém (BJ) publicada em 2002, que se apresenta como a "nova edição, revista e ampliada", é a tradução em língua portuguesa ${ }^{2}$ da edição francesa totalmente revisada de 1998 (BÍBLIA de Jerusalém, 2002). Sucederam-se, portanto, três versões da tradução da BJ no Brasil: 1) a primeira edição, de 1981, em formato grande, baseada na edição francesa de 1973; 2) a revisão literária desta, feita em 1989, também baseada na edição francesa de 1973; 3) a "nova edição, revista e ampliada", de 2002, baseada na edição francesa, totalmente revisada, de 1998.

Essa nova edição se distingue das anteriores, sobretudo, pelas introduções e notas de rodapé, que são mais atuais. Em termos editoriais, apresenta-se melhor que a segunda edição brasileira (a "gorduchinha").

1 Em muitos casos é impossível dizer qual foi a forma original dos textos bíblicos. A Bíblia de uso cristão reflete, tanto no cânon como na forma textual, o tempo das origens cristãs. Nesse sentido, é altamente questionável a eliminação dos livros deuterocanônicos com o pretexto de que não pertencem à Bíblia judaica. Por outro lado, dever-se-ia dar mais atenção à Septuaginta, que era a "Escritura" para a maioria dos primeiros cristãos.

2 Os direitos autorais incluem "exclusividade para a língua portuguesa em todo o mundo" (p. 4). 
Ficou mais fina, mas o texto mais apertado prejudica a leitura, principalmente, das referências na margem. A execução gráfica dessas referências causou também certo número de falhas ${ }^{3}$.

A qualidade científica tem o selo da École Biblique de Jérusalem. Como especialista no Novo Testamento, acostumado às opções textuais de Nestle-Aland (NESTLE-ALAND, 2009), parece-me que as escolhas de crítica textual-documental, na BJ, preferem, às vezes com demasiada facilidade, lições de manuscritos não gregos (sobretudo siríacos), mas isso geralmente não afeta o teor do texto, a não ser em alguns casos com os quais dificilmente posso concordar - questões a serem disputadas inter doctores $^{4}$. De qualquer modo, a BJ continua sendo um instrumento indispensável para quem, no Brasil, quer estudar a Bíblia com um mínimo de cientificidade.

\section{A Bíblia sagrada de Aparecida}

Em 2006, a Editora Santuário substituiu sua edição brasileira da Bíblia sagrada dos Capuchinhos do Porto por uma tradução produzida em terra brasileira (BÍBLIA ... Aparecida, 2006), fruto do trabalho sábio e competente do Pe. José Raimundo Vidigal, que teve também participação nas traduções anteriores da Liga de Estudos Bíblicos, da Editora Vozes e da CNBB. A qualidade exegética é do mesmo nível que as citadas traduções, e o estilo destaca-se pela notável elegância e simplicidade, transitando sempre entre o formal e o pastoral. Usa o tratamento na segunda pessoa (tu/vós) e transcreve o tetragrama do nome de Deus como Javé. Exibe duas categorias de notas de rodapé: uma com os textos paralelos, outra com explicações literárias ou teológicas pontuais. O uso do tipo gráfico Arial é uma das características que talvez favoreçam a legibilidade e, por isso, a popularidade.

3 São frequentes os erros da transposição eletrônica; por exemplo, a referência a Ex 26-28 ao lado de Ap 18,9 deve ser Ez 26-28 (BÍBLIA de Jerusalém, 2002, p. 2160).

4 Exemplos: Jo 13,10 (exclusão de "senão os pés") e Jo 11,25 (exclusão de "e a vida"). 


\section{A Nova tradução na linguagem de hoje no âmbito católico}

As Edições Paulinas publicaram a Nova tradução na linguagem de hoje (NTLH), embora de origem protestante, com os livros deuterocanônicos, que caracterizam as edições católicas e ecumênicas. A edição das Paulinas foi publicada primeiramente para Angola e Moçambique, mas logo depois adotada no Brasil (BÍBLIA... Paulinas, 2003). O Novo Testamento e os livros protocanônicos do Antigo Testamento pertencem à Nova tradução na linguagem de hoje da Sociedade Bíblia do Brasil (copyright de 2000), enquanto os textos deuterocanônicos do Antigo Testamento são das Sociedades Bíblicas Unidas (copyright de 2003). A ortografia dos nomes próprios segue a tradição protestante e as introduções e notas são mínimas, como na edição protestante. O tratamento é feito com os pronomes "você(s)" para os humanos e "tu" para Deus, que é chamado de "o Senhor" (= YHWH).

O mesmo procedimento segue a Bíblia sagrada: nova tradução na linguagem de hoje com método Lectio Divina, publicada pelas Sociedades Bíblicas Unidas, com o apoio das autoridades católicas (BÍBLIA... Unidas, 2012). A tradução bíblica e as introduções e notas são idênticas às da edição das Paulinas, mas o conjunto vem precedido de exemplos de lectio divina para os diversos livros da Bíblia ("Como fazer"). A iniciativa é valiosa, porque a NTLH tem boa aceitação entre os jovens de diversas confissões cristã ${ }^{5}$, os quais assim são conduzidos a fazer uma hermenêutica existencial e social do texto bíblico, em vez de cair no espontaneísmo ou no fundamentalismo que facilmente se apoiam nas traduções tradicionais.

\section{A Nova Bíblia pastoral}

Quando foi lançada, de forma completa, no ano de 1990, a Bíblia sagrada: edição pastoral teve grande aceitação, sobretudo na catequese, nas comunidades de base, nos grupos de estudo bíblico à luz da realidade e

5 Cf. o projeto "Lectionautas", que "busca capacitar jovens católicos a ler a Bíblia com o método de oração contemplativa chamado Lectio Divina” (LECTIONAUTAS BRASIL, 2015). 
na teologia da libertação. As razões disso eram seu estilo mais popular (vocabulário, tratamento por "você(s)"), o uso do nome próprio Javé, acentuando que ele é o Deus de Israel que escuta e liberta seu povo ${ }^{6}$, e as notas e introduções que alimentavam uma hermenêutica nesse mesmo sentido. Sabe-se que essa orientação provocou reação nos círculos eclesiásticos, o que ensejou algumas leves adaptações nas primeiras edições.

Chegou, entretanto, o momento de uma revisão mais profunda, que veio à luz com o título de Nova Bíblia pastoral (doravante NBP) (NOVA..., 2014). O "novo" se verifica, sobretudo, nas introduções e nas notas, que, por um lado, evitam certa unilateralidade e repetitividade presente nas edições anteriores e, por outro, aproveitam o progresso do estudo sócio-histórico-literário da Bíblia para sustentar a hermenêutica libertadora. Porém, algumas vezes tem-se a impressão de que a abordagem sócio-histórica predomina demais, a ponto de esconder o que o leitor popular deve saber antes de tudo: o dado narrativo, a "história narrada" na passagem em questão e a informação básica para sua compreensão de superfície. Certamente as futuras edições corrigirão isso. Já os subtítulos de cada passagem são bem mais objetivos do que nas edições anteriores (em que eles exprimiam antes a interpretação do que a matéria narrada).

A tradução do texto bíblico propriamente conserva as características anteriores (linguagem simples, tratamento por "você(s)", nome de Javé), porém ficou mais elegante, evitando pronomes supérfluos etc. Entretanto, algumas opções de crítica textual surpreendem. Assim, em João 1,13, a lição "eles [os fiéis] não nasceram do sangue, nem da vontade da carne, nem da vontade do varão, mas de Deus", hoje universalmente reconhecida como texto original, foi substituída pelo singular "ela [a Palavra] não nasceu do sangue [...]". Com isso, o texto se aplica a Cristo em vez de aos fiéis. Porém, essa lição no singular, ausente dos manuscritos gregos, surgiu no século IV, na Igreja do Ocidente, sob influência dos dogmas cristológicos (Niceia) ${ }^{7}$. A Nova Vulgata, texto oficial

6 nome lahweh já estava sendo adotado na BJ, a qual, porém, não era destinada ao uso popular. A Ave-Maria usava (e usa ainda) "o Senhor", com apenas a letra inicial maiúscula, e não todo em caixa-alta, distintivo convencional para sinalizar a substituição do tetragrama YHWH.

7 Para o estado da discussão, cf. METZGER (1975, p. 196-197). 
da Igreja latina, publicado na esteira do Concílio Vaticano II, lê o plural (nati sunt), em pleno acordo com a teologia do Evangelho e das Cartas de João (NOVA..., 1986).

\section{A Bíblia tradução ecumênica (TEB)}

A Bíblia tradução ecumênica, comumente chamada de Tradução ecumênica da Bíblia (TEB), foi publicada no Brasil, de forma completa, em 1994, com base na edição francesa de 1989 (Antigo e Novo Testamentos, com introduções e notas) (BÍBLIA tradução ecumênica, 1994).

A tradução francesa e, consequentemente, a portuguesa, que procura seguir esta última, são de tipo antes semântico que literal. O nome de Deus é representado por "o SENHOR”. Houve uma edição com notas reduzidas (nos formatos médio e micro), a qual, porém, não foi reimpressa, pois o grande valor estava precisamente no caráter erudito e nas notas e introduções da edição completa. Não tinha muito sentido publicar só a tradução do texto bíblico, condicionada como estava pela ligação ao original francês e às notas correspondentes. Em 2004 apareceu, na França, uma edição revisada e provida de novas introduções, que foi parcialmente aproveitada na edição brasileira de 2014 (quanto às introduções do Pentateuco). A novíssima edição francesa, de 2010, traz uma grande inovação, que deverá ser repassada também à futura edição brasileira: além dos "deuterocanônicos católicos", já incluídos (Jt, Tb, 1-2 Mc, Sb, Sr e Br), ela contém os livros deuterocanônicos das Igrejas ortodoxas (3 e 4 Esdras, 3 e 4 Macabeus, a Oração de Manassés e o Salmo 151). Apresenta, ainda, uma ampla introdução geral aos livros deuterocanônicos, tendo em vista o caráter ecumênico. Além disso, houve melhoras significativas para evitar possíveis ambiguidades ou mal-entendidos causados por determinadas traduções tradicionais (por exemplo, em relação ao "Deus ciumento" e ao termo judeus). Espera-se que a futura edição brasileira aproveite essa atualização para aprimorar também a tradução dos textos já publicados. 


\section{Outras}

A Bíblia Sagrada da Editora Ave-Maria não traz novidades quanto à tradução, mas agora existe também como bíblia de estudo. A Bíblia do peregrino, da Editora Paulus, a Bíblia mensagem de Deus, da Editora Loyola (continuadora da Bíblia da Liga de Estudos Bíblicos), e a Bíblia sagrada da Editora Vozes continuam sem modificações, a não ser quanto à adaptação da língua portuguesa ao Novo Acordo Ortográfico.

\section{Considerações metodológicas}

Essa breve apresentação das novidades evidencia logo a questão do estilo de cada tradução. Por um lado, temos traduções de estilo mais formal, como a Bíblia de Jerusalém e as bíblias da CNBB, da Editora Vozes, da Ave-Maria e a Mensagem de Deus, da Editora Loyola. Por outro lado, as traduções da Bíblia do peregrino, da Nova Bíblia pastoral e, sobretudo, a NTLH (também nas edições católicas/ecumênicas) priorizam mais a dinâmica semântica. A Bíblia sagrada de Aparecida está no meio das duas tendências; já a TEB segue, na realidade, o princípio da tradução semântica, porém num nível erudito, menos acessível ao grande público.

Esse fenômeno nos faz refletir, mais uma vez, sobre o método de tradução. Diante da opção entre tradução formal e tradução dinâmica, não se trata de "amar um e odiar o outro". Trata-se de articular os dois tipos. O uso da Bíblia por comunidades e indivíduos tem muitos aspectos e funções. Quando se trata de inscrever em nosso horizonte atual o "acontecer do sentido"8 ensejado pelo texto, uma tradução por equivalência semântica é mais indicada. Exemplo extremo de tal dinâmica é a tradução, por Antônio Houaiss, de Ulisses de James Joyce, na qual às vezes só os nomes próprios correspondem estritamente ao original (JOYCE, 1989).

A tradução dinâmica tem grandes vantagens para a leitura primeira, porque ela entra diretamente no mundo do leitor. Mas pode ficar devendo

8 Vemos o sentido essencialmente como um processo que se realiza entre 0 autor e 0 leitor/receptor, 0 qual colabora ativamente para o surgimento do significado. 
ao mundo do texto, por afastar-se das relações literárias e semânticas internas do texto, obliterando inclusive suas ligações históricas. Sem desvalorizar as bases científicas em que se baseiam essas traduções ${ }^{9}$, convém apontar os limites desse método. Um dos maiores inconvenientes é a desmetaforização, ou seja, a substituição de certas metáforas por conceitos supostamente claros para qualquer leitor, como se fosse possível despir de sua veste metafórica o que a metáfora quer evocar. Sabemos hoje que vivemos num mundo de metáforas (LAKOFF; JOHNSON, 1980). Mas a questão é se essas metáforas podem ser substituídas por outras expressões semanticamente equivalentes ou se elas trazem consigo uma história e uma inter-relação com o conjunto e o mundo das Escrituras - nesse caso, sua substituição se torna problemática. Um exemplo típico de empobrecimento é a substituição da polissêmica metáfora do "beber no próprio poço", em Provérbios 5,15, pelo correto, mas insípido, moralismo "seja fiel à sua mulher" (NTLH). Vale mais deixar o leitor participar no misterioso deslinde da metáfora. Aliás, a língua portuguesa popular está repleta de inúmeras metáforas e idiomatismos bíblicos, os quais seria uma pena perder (SOUZA, 1990). Quando a tradução substitui a forma da linguagem original, ela corre também o risco de enclausurar em conceitos o sentido do texto bíblico ${ }^{10}$, enquanto "o poético" desse texto consiste exatamente em criar um sentido aberto (MENDONÇA, 2014). Um exemplo desse enclausuramento indevido são as tentativas de redizer o texto em termos ideológicos.

Outro problema relacionado com a equivalência semântica é que "o homem (e a mulher) não vive(m) só de semântica”. A ciência literária clássica insistia muito no "valor sentimental" (Gefühlswert) ou na valoração subjetiva por parte do leitor, de que tornaremos a falar e que faz parte do mundo deste. Esse assunto não é meramente sentimental, mas semiótico. A valoração codetermina a significação. Assim, entende-se certa indignação quando a edição católica da NTLH (BÍBLIA..., 2003; BÍBLIA..., 2012) traduz Eclo 22,1: "O preguiçoso é como um pedaço de papel higiênico usado" (o grego sugere uma "pedra suja”).

9 Essas bases científicas podem agora ser encontradas na introdução do Léxico grego-português do Novo Testamento, de Johannes Louw e Eugene Nida (LOUW; NIDA, 2013).

${ }^{10}$ Suspeita-se que algumas traduções demasiadamente claras sejam inspiradas por certo positivismo linguístico. 
Voltando-nos agora para as traduções formais, lembramos que a Bíblia tem função de referência em relação às origens da tradição cristã. Essa função referencial é "conservadora", no bom sentido do termo. Uma Bíblia voltada em primeiro lugar para o uso litúrgico - como pretende ser a revisão em curso na $\mathrm{CNBB}$ - tem de manter a linguagem que sustenta toda a tradição da expressão da fé cristã e de sua vida litúrgica e sacramental. É uma linguagem que supõe iniciação, catequese. Uma tradução formal não serve para ser colocada no criado-mudo do quarto de hotel, pois não se aproxima do mundo do presumido leitor, mas serve para a comunidade que busca apropriação e celebração memorativa de sua fé. Evidentemente, ela será insuficiente para jovens e adultos que buscam uma compreensão mais direta e mais situada no mundo deles. Por isso, eles terão de completar a tradução formal e referencial com alguma outra tradução, mais dinâmica - conscientes, porém, de que esta não esgota seu sentido.

Apesar de sua limitação "comunicacional”, a tradução formal pode ter, hoje, uma função que dela não se esperaria: evitar o fundamentalismo. Ao crescente fundamentalismo e ao uso da Bíblia "ao pé da letra" (há até quem leia a NTLH "ao pé da letra"!) não se responde com traduções dinâmicas, porque elas são suspeitas de não trazer "a letra da palavra de Deus" (ainda que o tradutor tenha a certeza de representá-la melhor que a tradução formal). Um crente de tendência fundamentalista dificilmente se dignará conversar com base numa tradução mais livre, por mais que seja semanticamente acertada e, nesse sentido, "fiel". À leitura fundamentalista deve-se responder com uma tradução bíblica considerada "certa" (daí a preferência pela Almeida corrigida e fiel). É uma questão de psicologia. O leitor fundamentalista deverá descobrir a possível abertura do sentido num texto que se apresente claramente como próximo dos originais e que, por isso, inspire-lhe confiança. Nesse caso, não basta ser fiel (como se supõe que a tradução dinâmica seja), é também preciso parecer fiel (ou seja, que se confie na letra do texto)!

Em compensação, ao produzir uma tradução formal, cabe precaver-se de conceitos falsos que se apresentam sob a aparência de ortodoxia ou fidelidade literal. De um modo geral, válido para todas as culturas, pode-se dizer que muitos conceitos antigos são hoje valorados de modo 
diferente: a pena de morte, a homossexualidade, o radicalismo religioso, o patriarcalismo etc. Mesmo se entendemos esses conceitos em seu contexto histórico, constatamos que eles têm outro valor em nossa cultura atual, o que modifica a mensagem do texto para nós. A significância que produzem não é aquela que está no dicionário, nem mesmo naquele de Louw e Nida (2013)! A mensagem não é meramente nocional; ela comporta valores que se modificam segundo o tempo, a cultura, o contexto histórico e social e a voz do pregador...

Isso não significa que termos e imagens antigos e sujeitos a interpretação errônea devam, necessariamente, ser banidos e substituídos por conceitos menos conflitivos. É impossível eliminar da Bíblia o Deus guerreiro, a ideia do sacrifício etc., muito menos as metáforas quase espontâneas de céu, abismo, trevas, luz... Elas fazem parte dos próprios processos cognitivos (LAKOFF; JOHNSON, 1980). Devemos conhecer o modo de pensar de nossos ancestrais, mesmo se o nosso for diferente. Não adianta usar traduções edulcorantes, como "respeitar Deus" em vez de "temer Deus". Nossos pais na fé temiam e tremiam, mesmo. E é por isso que João, revolucionariamente, escreve que no amor perfeito não há temor (1Jo 4,18)... Só não devemos apresentar como palavra direta de Deus a valoração antiga desses conceitos. Devemos suscitar os leitores para uma Sachkritik: constatamos que nossos fundadores falaram e pensaram assim mesmo, mas agora cabe a nós decidir o que vamos pensar do pensamento deles.

Ora, a valoração de certos termos antigos pode ter evoluído de modo tão divergente que fica difícil reencontrar o valor original. Assim, sob o influxo do dualismo, a valoração negativa (ou seja, a desvalorização) do termo carne, como também a "desencarnação" do termo alma têm sido tão fortes que é preciso uma reeducação linguístico-semântica para que os leitores e ouvintes de hoje possam reencontrar o valor que esses termos evocavam nos primeiros destinatários.

Além disso, existe outro perigo, próprio das línguas neolatinas. As traduções clássicas nas línguas neolatinas são altamente influenciadas pela Vulgata de Jerônimo (mesmo a de Ferreira de Almeida). Ora, muitos termos usados no latim do século $\mathrm{V}$ d.C., por Jerônimo e seus contemporâneos (Agostinho, Leão Magno...), não têm o mesmo sentido que seus 
homônimos no português de hoje (por exemplo, mysterium/mistério, virtus/virtude, desiderium/desejo etc.). Conservar certos termos que parecem fiéis, porque "soam como latim", pode ser uma armadilha. Esses termos, foneticamente semelhantes aos da Vulgata, são entendidos por nós com uma carga que não tinham no tempo da redação dos textos bíblicos e dos seus tradutores antigos.

O anteriormente dito deixa claro que é impossível apropriar o acontecer original do sentido sem a fusão do horizonte antigo com o de hoje. E essa fusão exige a interpretação do texto no seu momento original. Daí a necessidade de se socializar para as nossas comunidades tanto a compreensão histórico-literária quanto a hermenêutica atualizada. É preciso trabalhar com os dois momentos da compreensão, o de ontem e o de hoje. Ora, esses momentos produzem estilos de tradução diferentes, e precisamos de ambos. O estilo formal, que deixa transparecer a estrutura e os conceitos do texto original, pode ser chamado de protocolar e referencial. Representa, em tradução, o texto que deve ser exibido como patrimônio fundamental de nossa tradição e ao qual se refere toda tradução, paráfrase e interpretação. Por outro lado, temos o tipo de tradução em que transparece mais a interpretação no horizonte atual: a tradução semanticamente dinâmica. Esta "decide" determinadas interpretações do texto que fazem sentido para uma parte dos leitores de hoje, mas não para todos, nem para todos os tempos. Por isso, é preciso voltar sempre à forma original, para "reabrir" seu potencial de sentido e, assim, "tirar do baú” coisas novas e antigas (Mt 13,52).

Tudo isso não é novo. Nas sinagogas da Palestina, no tempo de Jesus, lia-se primeiro o texto da Torá na língua hebraica, que se usava somente no culto, mas logo depois se lia o targum, ou transposição para o aramaico, a língua-irmã que todo mundo entendia na região (nas regiões de língua grega usava-se a tradução grega). Essa transposição, porém, não era uma tradução ao pé da letra, mas uma tradução atualizada, que introduzia referências à situação e aos interesses dos ouvintes, os quais também podiam tomar a palavra para interpretar e "profetizar". Ora, o targum nunca suplantou o texto hebraico, a tal ponto que, inicialmente, nem podia ser exposto por escrito. 
Existe, pois, certa semelhança entre os targuns e as traduções dinâmicas de hoje (RIBEIRO, 2009). Seria como se, hoje, o trecho bíblico fosse lido primeiro em tradução formal-protocolar e, depois, numa paráfrase ou tradução livre que explicasse o texto e o aplicasse à situação dos ouvintes, abrindo espaço para uma reflexão em comum, sem fechar definitivamente seu sentido.

\section{Referências}

BÍBLIA de Jerusalém: Nova edição revista e ampliada. São Paulo: Paulus, 2002. BÍBLIA Sagrada de Aparecida. Aparecida-SP: Santuário, 2006.

BIBLIA Sagrada: edição pastoral. São Paulo: Paulinas, 1990.

BÍBLIA Sagrada: nova tradução na linguagem de hoje com método Lectio Divina. São Paulo: Sociedades Bíblicas Unidas, 2012.

BÍBLIA Sagrada: nova tradução na linguagem de hoje. São Paulo: Paulinas, 2003. BÍBLIA tradução ecumênica: TEB. São Paulo: Loyola, 1994.

CNBB - CONFERÊNCIA NACIONAL DOS BISPOS DO BRASIL. Bíblia Sagrada. São Paulo: Loyola, 2001; com reedições revisadas sucessivas.

JOYCE, J. Ulisses. Trad. Antônio Houaiss. Oeiras: Livros do Brasil, 1989.

KONINGS, J. Tradução e traduções da Bíblia no Brasil. In: GOHN, Carlos (Org.). A Bíblia e suas traduções. São Paulo: Humanitas, 2009, p. 103-125.

KONINGS, J. A Bíblia, sua origem e leitura. 8.ed. Petrópolis, Vozes, 2014.

LECTIONAUTAS BRASIL. Disponível em: <https://pt-br.facebook.com/ LectionautasBrasil>. Acesso em: 26 jun. 2015.

LAKOFF, G.; JOHNSON, M. Metaphors we live by. Chicago/London: University of Chicago Press, 1980 (Port.): Metáforas da vida cotidiana. Belo Horizonte: UFMG, 1998). 
LOUW, J.; NIDA, E. Léxico grego-português do Novo Testamento. Barueri: Sociedade Bíblica do Brasil, 2013.

MENDONÇA, J. T. Leitura infinita: a Bíblia e a sua interpretação", Lisboa: Paulinas, 2014.

METZGER, B. M. et alii. A textual commentary on the Greek New Testament: a companion volume to the United Bible Societies Greek New Testament. London: United Bible Societies, 1975.

NESTLE-ALAND. Novum Testamentum graece. 27. ed. rev. Stuttgart: Deutsche Bibelgesellschaft, 2009.

NOVA Bíblia pastoral. São Paulo: Paulus, 2014.

NOVA Vulgata Bibliorum Sacrorum editio. 2. ed. Vaticano: Vaticana, 1986.

RIBEIRO, S. H. Traduções populares - os novos targumim? Belo Horizonte: FAJE, 2009368 f. Disponível em: <www.faculdadejesuita.edu.br/documentos/051212-dv091lxpLnEA6.pdf>

SOUZA, R. C. Palavra, parábola: uma aventura no mundo da linguagem. 2. ed. Aparecida: Santuário, 1990.

Recebido: 27/11/2015

Received: 11/27/2015

Aprovado: 15/01/2016 Approved: 01/15/2016 